\title{
Could nitric oxide be a mediator of action of oxytocin on myocardial injury in rats? (Biochemical, histological and immunohistochemical study)
}

\author{
Noha I. Hussien ${ }^{1}$ and Ayman M. Mousa ${ }^{2,3}$ \\ ${ }^{1}$ Department of Physiology, Benha Faculty of Medicine, Benha University, Cairo, Egypt \\ ${ }^{2}$ Department of Histology and Cell Biology, Benha Faculty of Medicine, Benha University, Cairo, Egypt \\ ${ }^{3}$ Department of Basic health Sciences, College of Applied Medical Sciences, Qassim University, Kingdom of Saudi Arabia
}

\begin{abstract}
Oxytocin (OT) was revisited recently as a hormone of cardiovascular system with several new functions in cardiovascular regulation. But less is known about its role in acute myocardial injury (MI). The aim of our study was to investigate the possible protective effect of OT on the biochemical, histological and immunohistochemical changes of MI induced by isoprenaline (ISO) in adult male albino rats and studying the possible role of nitric oxide (NO) in its action. Forty male albino rats were divided into 5 groups: control rats (Group I), acute MI rats (Group II), rats pretreated with OT prior to induction of MI (Group III), rats injected with a combination of OT and atosiban (ATO, OT receptor antagonist) prior to induction of MI (Group IV). In Group V, a combination of OT and nitric oxide synthase inhibitor (L-NAME) were injected to the rats prior to induction of MI. The heart wall in all groups were taken and processed for histological, immunohistochemical, morphometrical and biochemical studies. We concluded that OT has antioxidant, anti-inflammatory and anti-apoptotic effects on MI and its effects is mediated through NO.
\end{abstract}

Key words: Myocardial injury - Isoprenaline - Oxytocin — Atosiban — Nitric oxide - Apoptosis

Abbreviations: AMPK, AMP-activated protein kinase; ATO, atosiban; CAMKK, $\mathrm{Ca}^{2+} /$ calmodulin- $^{2}$ dependent protein kinase kinase; CPK, creatine phosphokinase; GSH-Px, glutathione peroxidase; ISO, isoprenaline; $\mathrm{LDH}$, lactate dehydrogenase; L-NAME, nitric oxide synthase inhibitor; MDA, malondialdehyde; MI, myocardial injury; MPO, myeloperoxidase activity; NF- $\kappa \mathrm{B}$, nuclear factor kappa-lightchain-enhancer of activated B cells; NO, nitric oxide; OT, oxytocin; OTRs, oxytocin receptors; PI3K, phosphoinositide 3-kinases; ROS, reactive oxygen species; TNF- $\alpha$, tumor necrosis factor-alpha.

\section{Introduction}

The myocardial tissue, unfortunately, has a limited capacity for regeneration and repair. So myocardial infarction is a major cause of morbidity and mortality worldwide, accounting for up to $40 \%$ of all deaths (Tawfik et al. 2010; Upaganlawar et al. 2010). Cell death, either progressive or acute, is a hallmark characteristic of various cardiac diseases, including myocardial injury (MI).

The heart is susceptible to numerous stresses that can cause MI. Once MI occurred, a vicious cascade of pathophysiological and biochemical alterations including hy-

Correspondence to: Noha I. Hussien, Department of Physiology, Faculty of Medicine, Benha University, Egypt

E-mail: drnohaibrahim79@gmail.com perlipidemia, thrombosis and lipid peroxidation leads to qualitative and quantitative changes of the myocardium. It has also been suggested that oxidative stress plays a major role in MI (Gaziano et al. 2010).

Apoptosis - the complex biological process characterized by cell shrinkage, chromatin condensation and DNA fragmentation - is involved in the pathogenesis of MI. Several protease families are implicated in apoptosis, the most prominent being caspases. In rat cardiomyocytes, it was shown that oxidative stress and the increase in concentrations of TNF- $\alpha$ are causative factors for apoptosis (Bae et al. 2010).

OT, a nanopeptide released from hypothalamic nerve terminals of the posterior pituitary, stimulates uterine contractions during parturition, milk ejection during lactation and is involved in cognition, tolerance, adaptation and complex sexual and maternal behavior. Indeed, recent studies indicate 
that equivalent concentrations of OT were found in the male pituitary, and stimuli for OT release were determined for both genders, suggesting other physiological functions for the hormone (Szeto et al. 2013).

OT is produced and released by the heart and acts on its cardiac receptors to decrease heart rate and force of contraction. Systemic administration of OT has significant effects on blood pressure, vascular tone and cardiovascular regulation (Szeto et al. 2008).

OT action and signaling are mediated by oxytocin receptors (OTRs), which are present in both the heart and large vessels. OTRs have been found in many other tissues as well. The size of OTRs in rat heart appears to be identical to those in the uterus and other organs. The presence of an OT antagonist in heart perfusion medium decreased not only OT effects, but also its basal release, indicating that the heart is a site of OT synthesis and supporting the hypothesis that these effects could be physiologically relevant (Paul-Clark et al. 2003).

OT was also shown to have transient negative inotropic and chronotropic effects on perfused isolated dog right atria in a mechanism mediated by NO production and acetylcholine release at cardiac parasympathetic postganglionic neurons (Menaouar et al. 2014).

While different synthetic drugs - with many adverse effects - are being used in managing heart diseases, oxytocin (OT) was recently revisited as a hormone of cardiovascular system with several protective and regulatory functions (Whelan et al. 2010). But less is known about its role in MI.

Based on this background, the present study aimed to evaluate the possible role of nitric oxide as a mediator for the protective effect of OT on isoprenaline (ISO)-induced acute $\mathrm{MI}$ in albino rats and to study the antioxidant, anti-apoptotic and anti-inflammatory effects of OT.

\section{Materials and Methods}

\section{Experimental animals}

All of the animals were approved by the Ethical Committee of the Faculty of Medicine, Benha University, Egypt. This study was conducted on 40,6-8 weeks old, adult male Sprague Dawley rats each weighing between 180 and $200 \mathrm{mg}$. Animals were housed in the animal laboratory at the medical research center at Benha Faculty of Medicine. They were allowed free access to water and standard diet.

\section{Chemicals}

Isoprenaline powder was supplied by Sigma Chemical (St. Louis, MO., USA). OT (syntocinon ampoule) was from Novartis Company and ATO (tractocile ampoule) - OT receptor antagonist - was from Ferring (Limhamn, Swe- den). As well as L-NAME - a nitric oxide synthase inhibitor - supplied by Sigma (St. Louis, MO, USA) and urethane from Sigma-Aldrich Chemie (Munich, Germany).

\section{Groups of the experiment}

The animals were randomly divided into 5 groups, each consisting of 8 rats. The groups are as follow: Group I (Control group) received only $0.5 \mathrm{ml}$ saline subcutaneously (s.c.) once a day for 2 successive days. Group II (MI group) received ISO hydrochloride $85 \mathrm{mg} / \mathrm{kg}$ s.c. dissolved in saline once daily for two successive days to induce MI (Rajadurai and Prince 2006). Group III (MI+OT group) received OT ( $0.5 \mathrm{mg} / \mathrm{kg} /$ day; s.c.) (Russell et al. 2004), one day before ISO-induced MI and continued to receive OT 20 minutes prior to s.c. injection of ISO for two successive days. Group IV (MI+OT+ATO group) received combination of OT as in Group III and ATO (1 mg/kg/day; intraperitoneally (i.p.)) (Russell et al. 2004) one day before ISO-induced MI and continued to receive OT and ATO 20 minutes prior to s.c. injection of ISO for two successive days. Group V (MI+OT+L-NAME group) received combination of OT as in Group III and L-NAME $(20 \mathrm{mg} / \mathrm{kg} /$ day i.p.) (Khatua et al. 2012) one day before ISO-induced MI and continued to receive OT and L-NAME 20 minutes prior to s.c. injection of ISO for two successive days.

Twenty-four hours after the last treatment, the rats were anesthetized by urethane in a dose of $1.25 \mathrm{~g} / \mathrm{kg}$ body weight dissolved in saline (Iwamoto et al. 1987). Thereafter, blood samples were collected from the retro-orbital plexus for estimation of creatine phosphokinase (CPK), lactate dehydrogenase (LDH) and nitrate levels. Rats were then sacrificed by decapitation and the hearts were rapidly isolated, washed with ice-cold saline and the left and right ventricles were divided equally to the samples. The right ventricles were homogenized in phosphate buffer $(\mathrm{pH} 7.4)$ to prepare homogenate that were used for the estimation of cardiac tumor necrosis factor alpha (TNF- $\alpha$ ), myeloperoxidase activity (MPO), caspase-3, glutathione peroxidase (GSH-Px) and malondialdehyde (MDA) contents, while the left ventricles were preserved in $10 \%$ formalin for histological and immunohistochemical examination.

\section{Biochemical assay}

At the end of the experimental protocol, serum CPK (Offerman et al. 1972) and LDH (King 1965), were measured by enzymatic colorimetric method (Bio-diagnostic, Egypt), while cardiac tissue TNF- $\alpha$ was measured by commercial sandwich Elisa kits for rats according to manufacturer's instructions (Sigma-Aldrich Co., St Louis, MO, USA) (Francis et al. 2004). Cardiac tissue caspase-3 activity was measured by Colorimetric Assay Kit from Bioscience (USA) and expressed as units/mg (Cai et al. 2002). MPO was measured 
as an index of neutrophil accumulation and was assessed using a commercial assay kit (Hycult Biotech Inc., Burlington, CA) (Rajadurai and Prince 2006). Plasma nitrate, the metabolic end-product of NO, was measured according to the method described by Bories and Bories (1995). In addition, lipid peroxidation in cardiac tissues was estimated by the determination of thiobarbituric acid reactive substances content that was evaluated as MDA in heart homogenate using a standard kit purchased from Biodiagnostic (Egypt) (Ndiaye et al. 2008) and cardiac GSH-Px content was determined using a commercial kit (Biodiagnostic, Egypt) (Ovize et al. 2010).

\section{Light microscopic study}

Tissue specimens were fixed in $10 \%$ neutral buffered formalin embedded in paraffin and cut in sequential $4-5 \mathrm{~mm}$ thick sections. These sections were stained with hematoxylin and eosin stain (H\&E) (Bancroft and Layton 2013).

\section{Immunohistochemical study}

Immunohistochemistry was used to localize the Bax antigen. Bax antibodies (Santa Cruz Biotechnology Inc.) were put at $4^{\circ} \mathrm{C}$ overnight. The appropriate horseradish peroxidase conjugated secondary antibodies were added and the samples were incubated for $1 \mathrm{~h}$ at room temperature (1:6,000 dilution for Bax) as described previously (Buytaert et al. 2006).

\section{Morphometric study}

The mean area $\%$ of Bax immunoreaction in cardiomyocytes was quantified in 10 images of high-power magnification $\times 1000$ for each Group using Image-Pro Plus program version 6.0 (Media Cybernetics Inc., Bethesda, Maryland, USA) in the Pathology Department, Faculty of Medicine, Benha University.

\section{Statistical analysis}

All the data are presented as mean \pm standard deviation (SD). Evaluation of differences between groups was performed using one-way analysis of variance (ANOVA) with SPSS 19.0 software. $p<0.05$ was considered statistically significant.

\section{Results}

\section{Mortality rate}

No rats died in the control, $\mathrm{MI}+\mathrm{OT}$ and in the $\mathrm{MI}+\mathrm{OT}+\mathrm{ATO}$ groups. Only one rat died in the MI Group with a mortality rate $(12.5 \%)$ and other one died in the Group that pretreated with OT and L-NAME (MI+OT+L-NAME group), with a mortality rate $(12.5 \%)$.

\section{Effect of OT and its combination with ATO and L-NAME on cardiac enzymes and nitrate levels in blood}

As shown in Table 1, injection of ISO leads to significant increase in serum CPK and LDH with significant $(p<0.001)$ decrease in plasma nitrate. Pretreatment with OT resulted in a significant $(p<0.001)$ decrease in serum CPK and LDH with significant increase in plasma nitrate when compared with Group II. The combination of OT and ATO prevents the effect of OT significantly $(p<0.001)$ when compared with Group III as well as it causes significant increase in CPK and LDH with significant decrease in nitrate when compared with Group II, indicating that ATO causes more deterioration in cardiac enzymes and nitrate levels. Combination of OT and L-NAME causes significant increase in CPK and LDH with significant decrease in nitrate when compared with Group III. By comparing Group V with Group II, there was significant decrease in serum CPK and LDH with significant decrease in plasma nitrate activity in Group V than Group II, indicating that although L-NAME causes significant decrease in OT protective effect on CPK and LDH, OT still has significant protective effect on cardiac enzymes levels.

Effect of OT and its combination with ATO and L-NAME on levels of cardiac TNF- $\alpha$, caspase- 3 activity and MPO activity

As shown in Table 2, injection of ISO leads to significant increase $(p<0.001)$ in cardiac TNF- $\alpha$ level, caspase- 3 and MPO activity. Pretreatment with OT leads to significant $(p<0.001)$ decrease in TNF- $\alpha$ level, caspase- 3 and MPO activity when compared with Group II. Combination of OT and ATO prevents the effect of OT significantly $(p<$ 0.001) when compared with Group III. Combination of OT and L-NAME causes significant $(p<0.001)$ increase in

Table 1. Effect of OT and its combination with ATO and L-NAME on $\mathrm{CPK}, \mathrm{LDH}$ and nitrate in ISO-induced MI rats

\begin{tabular}{lcccc}
\hline & \multicolumn{3}{c}{ Parameter } & \\
\cline { 2 - 4 } & CPK (U/l) & LDH (U/l) & Nitrate $(\mathrm{ng} / \mathrm{ml})$ & \\
\hline Group I & $244.4 \pm 2.5$ & $217.6 \pm 3.34$ & $17.6 \pm 1.06$ & 8 \\
Group II & $390 \pm 2.9^{\mathrm{a}}$ & $338.4 \pm 6.60^{\mathrm{a}}$ & $10.6 \pm 0.98^{\mathrm{a}}$ & 7 \\
Group III & $298.4 \pm 4.0^{\mathrm{b}}$ & $245.5 \pm 2.83^{\mathrm{b}}$ & $20 \pm 1.07^{\mathrm{b}}$ & 8 \\
Group IV & $411 \pm 2.1^{\mathrm{cb}}$ & $367.9 \pm 4.45^{\mathrm{cb}}$ & $9 \pm 1.3^{\mathrm{cb}}$ & 8 \\
Group V & $352.6 \pm 8.7^{\mathrm{bc}}$ & $306 \pm 6.2^{\mathrm{bc}}$ & $6.7 \pm 0.76^{\mathrm{bc}}$ & 7 \\
\hline
\end{tabular}

a significant difference $(p<0.001)$ compared with Group I (control group); ${ }^{\mathrm{b}}$ significant difference $(p<0.001)$ compared with Group II (MI group); ${ }^{c}$ significant difference $(p<0.001)$ compared with Group III (MI+OT group). Data are mean \pm SD. 
Table 2. Effect of OT and its combination with ATO and L-NAME on TNF- $\alpha$, caspase- 3 and MPO in ISO-induced MI rats

\begin{tabular}{lcccc}
\hline & \multicolumn{3}{c}{ Parameter } & \\
\cline { 2 - 4 } & $\begin{array}{c}\text { TNF- } \alpha \\
(\mathrm{pg} / \mathrm{mg})\end{array}$ & $\begin{array}{c}\text { Caspase-3 } \\
(\mathrm{u} / \mathrm{mg})\end{array}$ & $\begin{array}{c}\text { MPO } \\
(\mathrm{u} / \mathrm{gm})\end{array}$ & \\
\hline Group I & $26.8 \pm 1.7$ & $4.5 \pm 0.18$ & $0.79 \pm 0.08$ & 8 \\
Group II & $58.1 \pm 1.9^{\mathrm{a}}$ & $12.4 \pm 0.22^{\mathrm{a}}$ & $2.4 \pm 0.74^{\mathrm{a}}$ & 7 \\
Group III & $35.4 \pm 1.6^{\mathrm{b}}$ & $5.8 \pm 0.15^{\mathrm{b}}$ & $0.98 \pm 0.13^{\mathrm{b}}$ & 8 \\
Group IV & $67.3 \pm 1.7^{\mathrm{cb}}$ & $13.8 \pm 0.1^{\mathrm{cb}}$ & $3.08 \pm 0.15^{\mathrm{c} \&}$ & 8 \\
Group V & $53.7 \pm 3.07^{\mathrm{c} \&}$ & $8.9 \pm 0.35^{\mathrm{cb}}$ & $2.03 \pm 0.3^{\mathrm{c}}$ & 7 \\
\hline
\end{tabular}

a significant difference $(p<0.001)$ compared with Group I (control group); ${ }^{\mathrm{b}}$ significant difference $(p<0.001)$ compared with Group II (MI group); ${ }^{\mathrm{c}}$ significant difference $(p<0.001)$ compared with Group III (MI+OT group); ${ }^{\&}$ significant difference $(p<0.01)$ compared with Group II (MI group). Data are mean \pm SD.

TNF- $\alpha$ level, caspase-3 and MPO activity when compared with Group III. By comparing Group IV with Group II, there was significant increase in TNF- $\alpha$ level, caspase-3 and MPO activity in Group IV than Group II, indicating that ATO causes more deterioration in inflammation and apoptosis. By comparing Group V with Group II, there was significant decrease in TNF- $\alpha$ level and caspase-3 activity in Group V than Group II, indicating that although L-NAME causes significant decrease in OT protective effect on TNF- $\alpha$ level, caspase-3 and MPO activity; OT still has significant anti-inflammatory and anti-apoptotic effect.

Effect of $O T$ and its combination with ATO and L-NAME on levels of cardiac MDA and GSH-Px activity

As shown in Table 3, injection of ISO leads to significant increase $(p<0.001)$ in cardiac MDA and significant decrease $(p<0.001)$ in GSH-Px activity. Pretreatment with OT leads to

Table 3. Effect of OT and its combination with ATO and L-NAME on MDA and GSH-Px in ISO-induced MI rats

\begin{tabular}{lccc}
\hline & \multicolumn{2}{c}{ Parameter } & \\
\cline { 2 - 3 } & $\begin{array}{c}\text { MDA (nmol/g tis- } \\
\text { sue) }\end{array}$ & GSH-Px (u/mg) & \\
\hline Group I & $6.3 \pm 0.47$ & $5.8 \pm 0.36$ & 8 \\
Group II & $11.8 \pm 0.43^{\mathrm{a}}$ & $2.8 \pm 0.39^{\mathrm{a}}$ & 7 \\
Group III & $8 \pm 0.22^{\mathrm{b}}$ & $5 \pm 0.17^{\mathrm{b}}$ & 8 \\
Group IV & $15.9 \pm 0.79^{\mathrm{bc}}$ & $1.9 \pm 0.3^{\mathrm{bc}}$ & 8 \\
Group V & $10.6 \pm 1.3^{\mathrm{cc}}$ & $3.7 \pm 0.4^{\mathrm{bc}}$ & 7 \\
\hline
\end{tabular}

a significant difference $(p<0.001)$ compared with Group I (control group); ${ }^{b}$ significant difference $(p<0.001)$ compared with Group II (MI group); ${ }^{\mathrm{c}}$ significant difference $(p<0.001)$ compared with Group III (MI+OT group); ${ }^{\&}$ significant difference $(p<0.05)$ compared with Group II (MI group). Data are mean \pm SD. significant $(p<0.001)$ decrease in MDA level, and significant increase in GSH-Px activity when compared with Group II. Combination of OT and ATO prevents the effect of OT significantly $(p<0.001)$ when compared with Group III. Combination of OT and L-NAME causes significant $(p<0.001)$ increase in MDA and significant decrease in GSH-Px activity when compared with Group III. By comparing Group IV with Group II, there was significant increase in MDA and significant decrease in GSH-Px activity in Group IV than Group II, indicating that ATO causes more deterioration in oxidative stress and lipid peroxidation. By comparing Group V with Group II, there was significant decrease in MDA level and significant increase in GSH-Px activity in Group V than Group II, indicating that although L-NAME causes significant decrease in OT protective effect on MDA and GSH-Px activity, OT still has significant protective effect on oxidative stress and lipid peroxidation.

\section{Histological change}

Myocardial sections from Group I stained with H\&E showed normal appearance of rat's myocardium, branching and anatomizing of cardiac muscle fibers with acidophilic myofibrils in sarcoplasm and central elongated vesicular nuclei and interstitial tissue. The interstitial tissue contained oval fibroblasts and few collagen fibers in-between the muscle fibers (Fig. 1A). Myocardial sections from rats injected with ISO in Group II showed abnormal cardiomyocytes. Most cardiomyocytes had multiple focal areas of myocardial degeneration with deeply acidophilic cytoplasm, vacuoles and deeply stained central nuclei. The interstitial tissue contained wide spaces with edema, oval fibroblasts, few collagen fibers and wide areas of hemorrhage in-between the muscle fibers (Fig. 1B).

A marked improvement was noticed in rats pretreated with OT in Group III. There were branching and anatomizing cardiac muscle fibers with acidophilic sarcoplasm and central elongated vesicular nuclei and interstitial tissue. The interstitial tissue contained oval fibroblasts and few collagen fibers in-between the muscle fibers (Fig. 1C).

On the other hand, pretreatment with OT in combination with ATO in Group IV showed no improvement in the abnormal cardiomyocytes. Most cardiomyocytes had deeply acidophilic cytoplasm and deeply stained nuclei. The interstitial tissue showed oval fibroblasts in-between the muscle fibers and wide areas of hemorrhage around the blood vessels (Fig. 1D).

Combination of OT with L-NAME in Group V showed a slight improvement in cardiomyocytes. There was a branching and anatomizing cardiac muscle fibers with acidophilic sarcoplasm and central elongated vesicular nuclei. The interstitial tissue showed oval fibroblasts, few collagen fibers in-between the muscle fibers and small areas of hemorrhage around the blood vessels (Fig. 1E). 
A

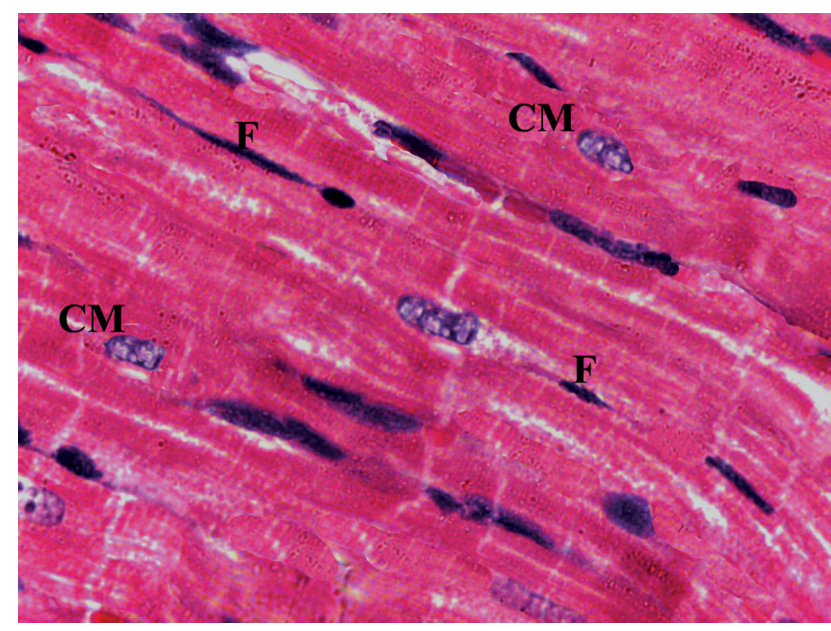

B

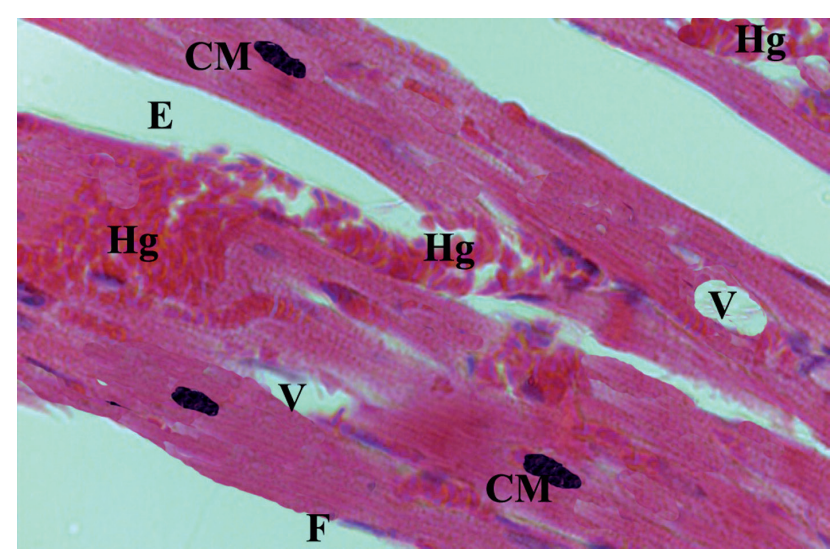

C

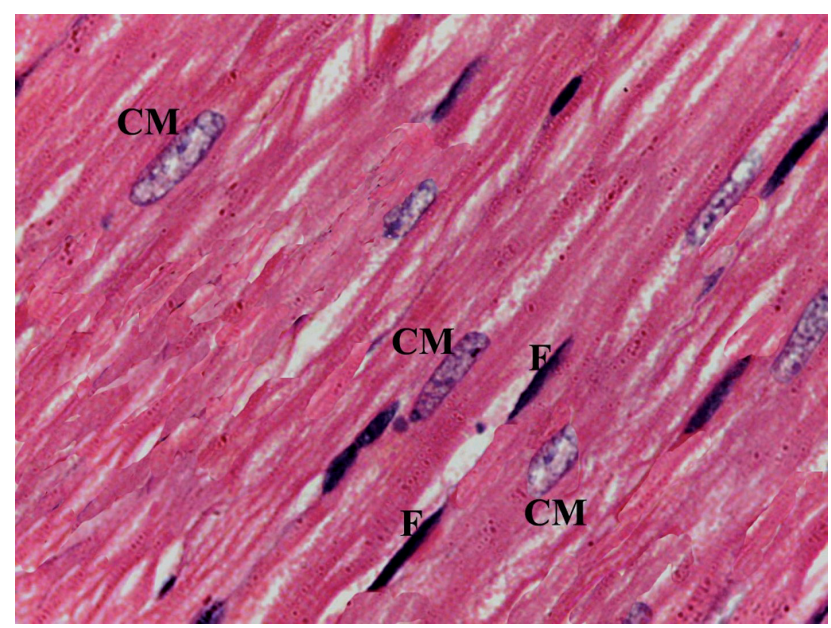

D

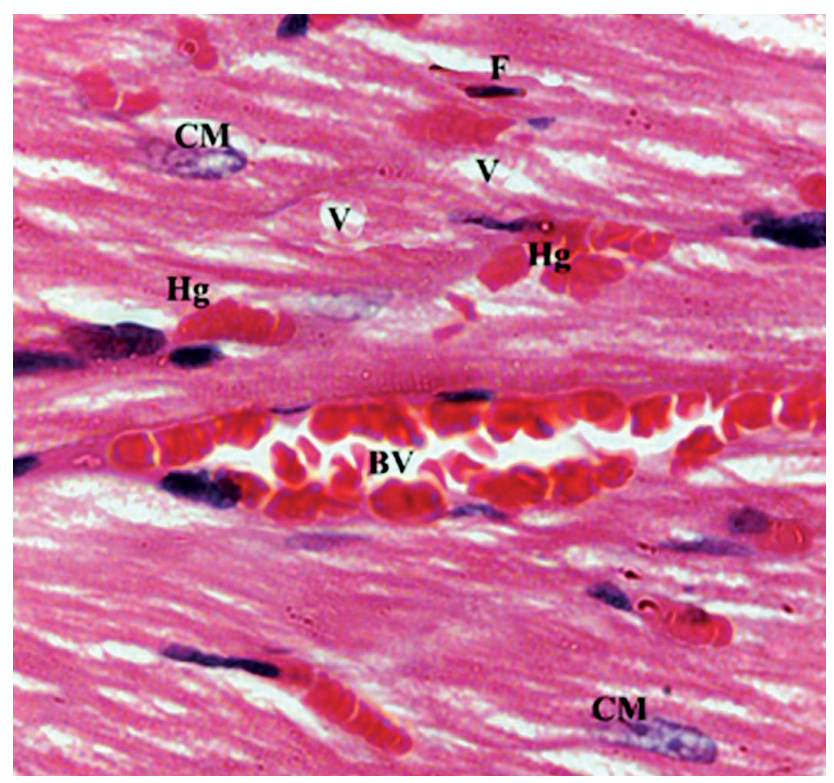

$\mathbf{E}$

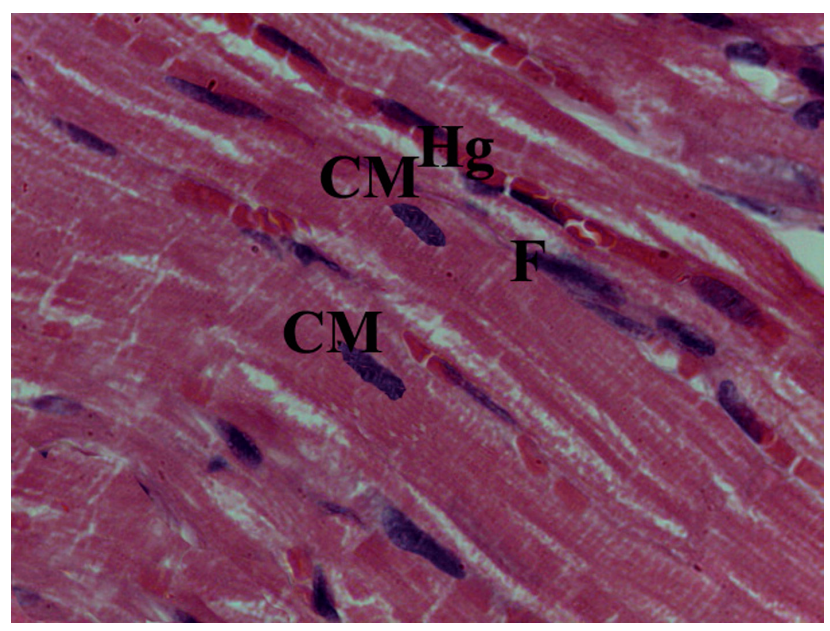

Figure 1. Histological changes of rat left ventricles stained with H\&E. A. Group I showing normal cardiomyocytes (CM). The interstitial tissue contains oval fibroblasts (F) and few collagen fibers in-between the muscle fibers. B. Group II showing abnormal CM with deeply acidophilic cytoplasm and vacuoles (V). The interstitial tissue contains wide spaces with edema (E), oval fibroblasts (F), few collagen fibers and wide areas of hemorrhage $(\mathrm{Hg})$ in-between the muscle fibers. C. Group III showing marked improvement in CM and interstitial tissue. D. Group IV showing abnormal CM with a deeply acidophilic cytoplasm and deeply stained nuclei. The interstitial tissue shows oval fibroblasts (F) in-between the muscle fibers and wide areas of hemorrhage $(\mathrm{Hg})$ around a blood vessel (BV). E. Group V showing normal CM and the interstitial tissue shows small areas of hemorrhage $(\mathrm{Hg})$ in-between the muscle fibers $(H \& E \times 1000)$. 


\section{Immunohistochemical change}

As shown in Fig. 2A, myocardial sections from Group I showed negative immunostaining reaction for Bax in the branching and anatomizing cardiac muscle fibers. It was demonstrated that the level of Bax expression was increased in Group II (Fig. 2B), while, the treatment with OT decreased cardiomyocyte apoptosis and infarct size by decreasing the expression of Bax (Fig. 2C). On the other hand, pretreatment with OT in combination with ATO in Group IV showed no improvement as Bax expression was

\section{A}

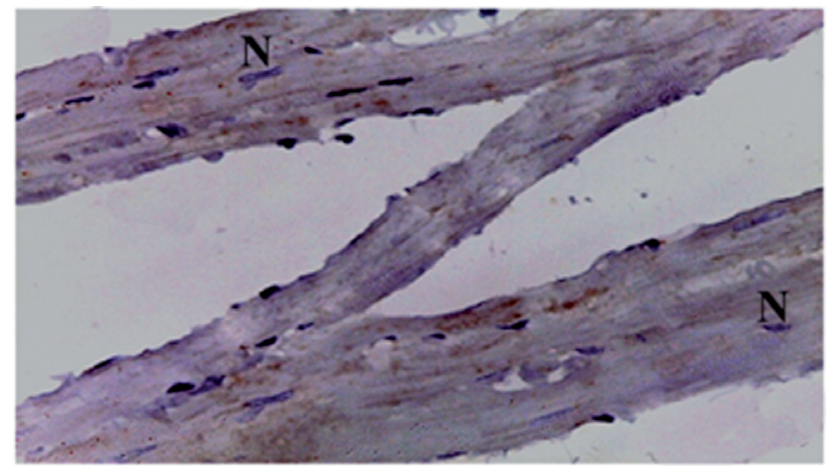

\section{B}

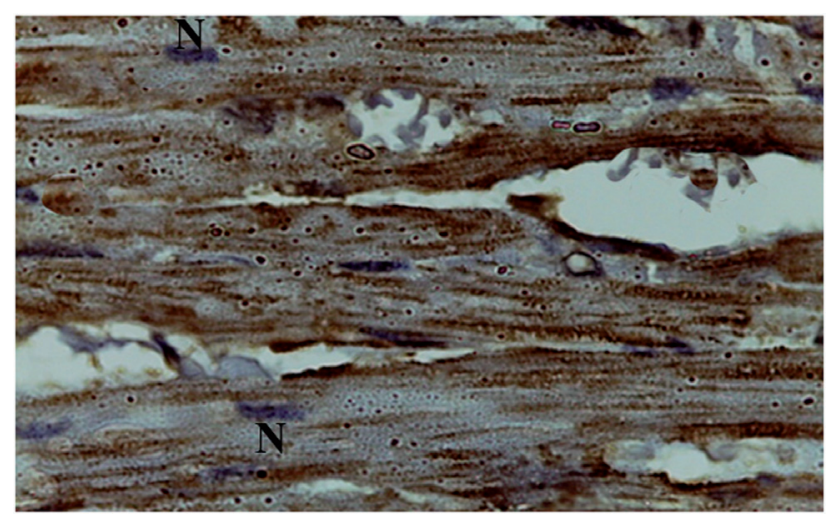

C

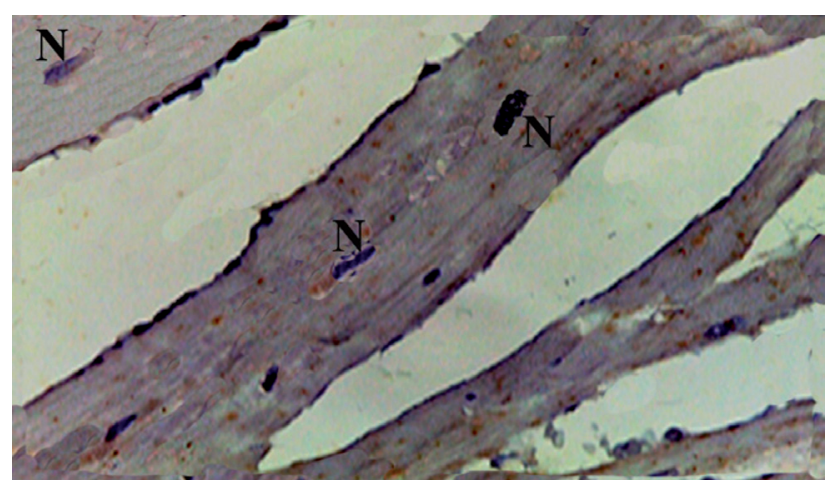

increased (Fig. 2D), while combination of OT with L-NAME in Group V led to slight improvement as Bax expression was slightly decreased (Fig. 2E).

\section{Morphometric results}

The mean area\% of Bax immunoreaction for cardiomyocytes in all groups in the present study is presented in Table 4. There was a significant increase in Group II compared with Group I. A significant decrease was seen in Group III when compared with Group II and a significant increase

\section{D}

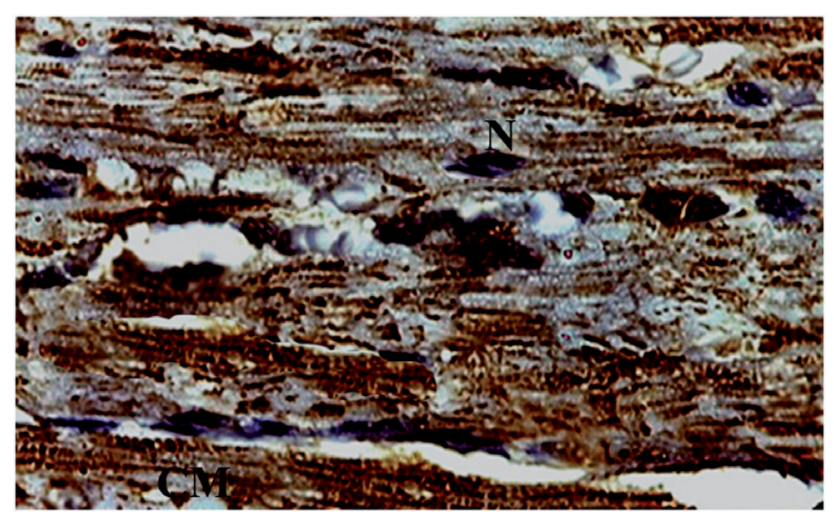

E

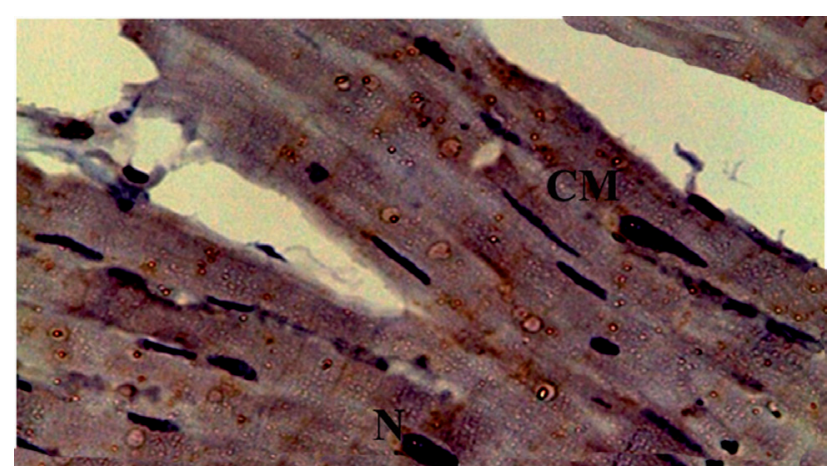

Figure 2. Immunostaining reaction for Bax. Photomicrographs of Bax immune-stain reaction stained heart sections. A. Group I showing -ve immune-stain reaction for Bax in the branching and anastomosing cardiac muscle fibers. The nuclei of cardiomyocytes are central and stained blue (N). B. Group II showing +ve immunestain reaction for Bax. C. Group III showing -ve expression of Bax immune-stain reaction. D. Group IV showing +ve expression of Bax immune-stain reaction. E. Group V showing slightly +ve expression of Bax immune-stain reaction. Bax immune-staining $\times 1000$. 
for Bax immunoreaction in Group IV and Group V when compared with Group III. There was significant increase in Bax immunoreaction in Group IV when compared with MI group indicating that ATO causes decrease in the protective effect of endogenous OT. As well as combination of OT with L-NAME in MI rats showed significant decrease in the Bax immunoreaction when compared with MI group indicating that in spite of significant decrease in the protective effect of OT it still has protective effect.

\section{Discussion}

ISO-induced MI is widely used experimental model that is associated with marked myocardial ischemia. Several mechanisms proposed to explain the ISO-induced MI include an unbalance between oxygen supply and demand of cardiomyocytes, which is related to myocardial hyperfunction due to increase in chronotropism and inotropism (Madhesh et al. 2011). Eventually, it causes severe oxidative stress in the myocardium, which results from a serious imbalance between the generation of reactive oxygen species (ROS) and their clearance by the body's endogenous anti-oxidative defenses. Also it stimulates lipid peroxidation, which may be a causative factor for damage to the myocardial membrane (Mahammad and Kodidhela 2013), so cytosolic enzymes such as LDH and CPK were released into blood stream and serve as diagnostic markers of myocardial tissue damage. The amount of these cellular enzymes present in blood reflects the alterations in plasma membrane integrity and/ or permeability (Gürgün et al. 2008).

The injured region undergoes myocyte apoptosis resulting in complement activation, free radicals generation, and an accumulation of cellular debris. Phagocytosis of the resultant cellular debris by macrophages and neutrophils triggers the inflammatory cytokines as TNF- $\alpha$ (Frangogiannis et al. 2002; Szeto et al. 2013). There are two pathways that activate apoptosis during acute MI: one depends on the mitochondria called intrinsic pathway that caused by up regulation of Bax, a pro-apoptotic member of Bcl-2 family proteins (Buytaert et al. 2006), and the other depends on the cell surface receptors, like TNF-a receptor, called extrinsic pathway that depends on increase of TNF-a (Lee and Gustafsson 2009). Both pathways end by activation of caspase-3 leading to cell death. MI induced by ISO is associated with down-regulation of eNOS and up-regulation of iNOS expression (Wsol et al. 2008). Förstermann et al. (1994) reported that eNOS was responsible for most of the NO produced by endothelium, so the decrease in nitrate level in plasma during MI may be caused by down-regulation of eNOS. So the current study revealed significant increase in serum CPK and LDH levels and significant increase in the MDA, caspase-3, TNF- $\alpha$ and MPO levels with significant
Table 4. Effect of OT and its combination with ATO and L-NAME on the mean area\% of Bax immunoreaction for cardiomyocytes in ISO-induced MI rats

\begin{tabular}{lcc}
\hline & $\begin{array}{c}\text { The mean area \% of Bax } \\
\text { immunoreaction }\end{array}$ & $n$ \\
\hline Group I & $0.88 \pm 0.05$ & 8 \\
Group II & $22.9 \pm 1.8^{\mathrm{a}}$ & 7 \\
Group III & $0.98 \pm 0.06^{\mathrm{b}}$ & 8 \\
Group IV & $24.1 \pm 1.5^{\mathrm{bc}}$ & 8 \\
Group V & $8.7 \pm 0.5^{\mathrm{bc}}$ & 7 \\
\hline
\end{tabular}

a significant difference $(p<0.001)$ compared with Group I (control group); ${ }^{\mathrm{b}}$ significant difference $(p<0.001)$ compared with Group II (MI group); ${ }^{\mathrm{c}}$ significant difference $(p<0.001)$ compared with Group III (MI+OT group). Data are mean \pm SD.

decrease in GSH-Px in the cardiac tissue and decrease in plasma NO of MI group when compared with the Control group. MI was further confirmed by histopathological studies and increase in Bax expression by immunohistochemical study. These results are in harmony with the previous studies (Förstermann et al. 1994; Frangogiannis et al. 2002; Buytaert et al. 2006; Gürgün et al. 2008; Wsol et al. 2008; Lee and Gustafsson 2009; Madhesh et al. 2011; Szeto et al. 2013).

The current study revealed that administration of OT caused significant reduction in ISO-induced elevated serum CPK and LDH enzymes. This reduction in enzyme levels could be due to its action on maintaining membrane integrity thereby restricting the leakage of these enzymes. These findings are in harmony with previous reports of Fariba et al. (2015) and Moghimian et al. (2012). Exogenous OT administration has direct negative chronotropic effects. Slowing of the heart rate leads to a decrease in myocardial consumption of oxygen and nutrients, and an increase in subendocardial blood flow per beat that may improve regional contractile function in a mechanism mediated by activation of eNOS and increase in NO production (Okinaka et al 1961). Also Gutkowska et al (2014) reported that OT increases glucose uptake in cardiomyocytes via the phosphoinositide 3-kinases (PI3K)/Akt/eNOS pathway, so blockage of eNOS enzyme by L-NAME leads to significant decrease in the protective effect of OT on cardiac enzymes indicating that NO is one of the mediators of action of OT on MI.

On the other hand, we found that blockage of the OT receptors by ATO prevented the cardioprotective effect of OT on cardiac enzymes. In addition, we showed that ATO increased CPK and LDH levels as compared with the MI group, indicating a probable protective role for endogenous OT in MI under experimental conditions. These results were in agreement with previous studies (Houshmand et al. 2009; Szeto et al. 2013).

In the current study pretreatment with OT caused significant decrease in TNF- $\alpha$ and MPO levels in the cardiac 
tissue. This can be explained by many studies (Ndiaye et al. 2008; Szeto et al. 2008) as they reported that OT treatment suppressed the accumulation of immune cells in infarcts, as identified by macrophage and T cell markers. Several subsets of T cells, like $\mathrm{CD} 4^{+}$and $\mathrm{CD} 8^{+}$, expressed OTR mRNA, indicating an important role for the OT system in the response of these immune cells. T cell infiltration is accompanied by monocyte/macrophage infiltration. Therefore, by primarily affecting T cells, OT can also limit monocyte/macrophage infiltration. On the other hand, recent studies indicate the presence of OTR in monocytes and macrophages, suggesting that these cells are direct targets of this hormone in inflammation. So in the present study combination of OT with ATO, OTR antagonist, leads to reversal of the anti-inflammatory effect of OT indicating that this effect is mediated by OTR. Moreover, OT was shown to increase corticosterone levels acutely in rats which are capable of inhibiting neutrophil extravasation in response to different stimuli (Szeto et al. 2013).

In addition, OT stimulates NO release by increasing NOS activity. NO inhibits adhesion and aggregation of neutrophils and has the capacity to interact with a variety of enzymes thereby altering their function and influencing inflammatory reactions. For example, NO can inhibit functions of many iron-containing enzymes. NO can reversibly inhibit cytochrome P-450 (Paglia and Valentine 1967; Palacios-Callender et al. 2004). NO can inhibit ribonucleotide reductase, an enzyme critical for the synthesis of DNA precursors. NO can inhibit transcriptional events by inhibiting the transcription factor nuclear factor kappa-light-chain-enhancer of activated $B$ cells (NF- $\kappa B$ ), which is a protein complex that controls transcription of DNA, cytokine production and cell survival. Incorrect regulation of NF- $\kappa \mathrm{B}$ has been linked to inflammatory reaction. This has been suggested to be an important mechanism underlying the anti-inflammatory actions of some NO-releasing drugs. So in the current study combination of L-NAME with OT caused significant increase in MPO and so decrease in its anti-inflammatory effect.

The present study also revealed that OT caused significant decrease in MDA with significant increase in GSH-Px indicating its antioxidant effect. The antioxidant properties of OT were proved by other studies (Szeto et al. 2008; Faghihi et al. 2013) which suggested that in MI, dysfunction in mitochondrial respiration may increase the formation of ROS, and NADPH oxidase generates ROS in the cytosol of cells. Also these studies showed that OT protects against ROS. It was demonstrated in cultured human vascular cells that OT decreases NADPH-dependent superoxide activity via a mechanism involving OTR. So in the present study we showed that combination of OT with ATO in Group IV leads to reversal of the antioxidant effect of OT.

In addition the balance between $\mathrm{NO}$ and oxidative stress is critical for the homeostatic functions of the intrinsic cardiovascular OT system (Menaouar et al. 2014), NO has been reported to be a free radical scavenger. The anti-oxidant capacity of plasma was found to be doubled by the administration of NO donors. It is possible that production of NO in amounts exceeding local production of superoxide anion leads to accelerated decomposition of peroxynitrite to nitrate and nitrite, thus reducing tissue exposure to peroxynitrite and to the hydroxyl radical that can be formed from peroxynitrite. In addition to acting as a superoxide scavenger, NO may also have the ability to prevent superoxide production from neutrophils by directly inhibiting NADPH oxidase. Thus, it was suggested that a lack of NO, following administration of a NOS inhibitor, resulted in an accumulation of superoxide anion that may then directly increase epithelial permeability, activate mast cells, or serve as a precursor for the production of more potent reactive oxygen metabolites (John 2005). So in this study combination of OT with L-NAME leads to decrease in the antioxidant effect of OT indicating that $\mathrm{OT}$ effects is mediated throughout its release of NO.

Biondi-Zoccai et al. (2004) showed that the amount of apoptosis in the initial (24 hours) of acute MI may be approximately $60 \%$ of cases demonstrate the presence of Bax or caspase- 3 activation. However, in the current study treatment with OT decreases cardiomyocyte apoptosis by decreasing the expression of Bax and decrease caspase-3 protein in cardiac tissue. The anti-apoptotic effect of OT can be explained by the $\mathrm{Ca}^{2+} /$ calmodulin/dependent protein kinase kinase (CAMKK) and AMP-activated protein kinase (AMPK) pathways that are involved in OT-mediated glucose uptake in the cardiomyocyte. As the activation of AMPK in the heart following $\mathrm{MI}$ is recognized as cardioprotective because AMPK limits apoptosis and cell damage (Russell et al. 2004). In this regard, Kewalramani et al. (2009) have defined AMPK as a powerful cardiac anti-inflammatory protector against TNF-a triggered cardiomyocyte apoptosis through the phosphorylation of Bad protein and the subsequently suppressed mitochondrial apoptotic signaling.

Alizadeh et al. (2011) and Ovizeet al. (2010) reported that the cardioprotective effect of OT is caused by selective activation of OTR, mitochondrial $\mathrm{K}_{\mathrm{ATP}}$ (mitoK $\mathrm{K}_{\mathrm{ATP}}$ ) channel and NO with blockade of mitochondrial permeability transition pore (mPTP). The effect of OT on mitochondria is mediated by NO that activates cGMP and protein kinase $\mathrm{G}$ (PKG). Indeed, PKG inhibits the opening of $\mathrm{MPTP}$ through the prolongation of intracellular acidosis, resulting in $\mathrm{Ca}^{2+}$ normalization.

So, in the present study combination of OT with L-NAME showed slight increase in positive immunostaining reaction for Bax indicating that the anti-apoptotic effect of OT on MI is partially mediated by NO. As well as combination of OT with ATO showed marked increase in positive immunostaining reaction for Bax. Our data suggested that 
treatment with OT might inhibit cardiomyocyte apoptosis, thus providing an anti-apoptosis strategy against MI. To the best of our knowledge, this is the first report that analyzes the effect of OT on the expression of Bax on the cardiac tissue of MI model.

In the current study we showed that although L-NAME causes significant decrease in OT protective effect on cardiac enzymes, oxidative stress, lipid peroxidation, inflammation, neutrophil infiltration and apoptosis, OT still has significant protective effect on all these parameters by comparing Group V with Group II. This can be explained as NO is not the only mediator of action of OT on MI for further studies.

We also reported that blocking of OT receptors by ATO caused significant increase in cardiac enzymes, TNF- $\alpha$, MDA and MPO with significant decrease in nitrate and GSH-Px levels in MI+OT+ATO group when compared with MI group, indicating that blocking of OT receptors caused more deterioration of MI. This may be due to abolishing the protective effect of endogenous OT.

\section{Conclusion}

In conclusion, the present study revealed that OT pretreatment attenuated oxidative stress, inflammatory reactions and apoptosis as well as declined tissue damage in ISOinduced $\mathrm{MI}$ in rats; in addition, it leads to increase in $\mathrm{NO}$ synthesis. OT effects are mediated through OTR and NO release.

Conflict of interest. We declare that there was no conflict of interest and we had not received any fund or grants.

\section{References}

Alizadeh A. M., Faghihi M., Sadeghipour H. R., Mohammadghasemi F., Khori V. (2011): Role of endogenous oxytocin in cardiac ischemic preconditioning. Regul. Pept. 167, 86-90 http://dx.doi.org/10.1016/j.regpep.2010.11.004

Bae S., Siu P. M., Choudhury S., Ke Q., Choi J.H., Koh Y.Y. (2010): Delayed activation of caspase-independent apoptosis during heart failure in transgenic mice overexpressing caspase inhibitor CrmA. Am. J. Physiol. 299, 1374-1381 http://dx.doi.org/10.1152/ajpheart.00168.2010

Bancroft J. D., Layton C. (2013): The hematoxylins and eosin with Connective tissue and stains. In: Bancroft's Theory and Practice of Histological Techniques. (Eds. S. K. Suvarna, C. Layton and J. D. Bancroft), 7th ed., pp. 187-214, Churchill Livingstone/ Elsevier, Philadelphia http://dx.doi.org/10.1016/B978-0-7020-4226-3.00011-1

Biondi-Zoccai G. G. L., Abbate A., Vasaturo F. (2004): Increased apoptosis in remote non-infarcted myocardium in multivessel coronary disease. Int. J. Cardiol. 94, 105-110 http://dx.doi.org/10.1016/j.ijcard.2003.07.001

Bories P. N., Bories C. (1995): Nitrate determination in biological fluids by an enzymatic one-step assay with nitrate reductase. Clin. Chem. 41, 904-907

Buytaert E., Callewaert G., Vandenheede J. R., Agostinis P. (2006): Deficiency in apoptotic effectors Bax and Bak reveals an autophagic cell death pathway initiated by photodamage to the endoplasmic reticulum. Autophagy 2, 238-240 http://dx.doi.org/10.4161/auto.2730

Cai L., Guangwu W., Luping G., Youchun J., James Y. K. (2002): Hyperglycemia-induced apoptosis in mouse myocardium mitochondrial cytochrome c-mediated caspase-3 activation pathway. Diabetes 51, 1938-1948 http://dx.doi.org/10.2337/diabetes.51.6.1938

Faghihi M., Alizadeh A. M., Khori V., Latifpour M., Khodayari S. (2012): The role of nitric oxide, reactive oxygen species, and protein kinase $\mathrm{C}$ in oxytocin-induced cardioprotection in ischemic rat heart. Peptides 37, 314-319 http://dx.doi.org/10.1016/j.peptides.2012.08.001

Fariba H., Mahdieh F., Saleh Z. (2015): Role of atrial natriuretic peptide in oxytocin induced cardioprotection. Heart Lung Circ. 24, 86-93 http://dx.doi.org/10.1016/j.hlc.2014.05.023

Förstermann U., Closs E. I., Pollock J. S., Nakane M., Schwarz P., Gath I. (1994): Nitric oxide synthase isozymes: characterization, purification, molecular cloning, and functions. Hypertension 23, 1121-1131 http://dx.doi.org/10.1161/01.HYP.23.6.1121

Frangogiannis N. G., Wayne-Smith C., Entman M. L. (2002): The inflammation response in myocardial infarction. Cardiovasc. Res. 53, 31-47 http://dx.doi.org/10.1016/S0008-6363(01)00434-5

Gaziano T. A., Bitton A., Anand S., Abrahams-Gessel S., Murphy A. (2010): Growing epidemic of coronary heart disease in low- and middle-income countries. Curr. Probl. Cardiol. 35, 72-115 http://dx.doi.org/10.1016/j.cpcardiol.2009.10.002

Gürgün C., Ildizli M., Yavuzgil O., Sin A., Apaydin A., Cinar C., Kültürsay H. (2008): The effects of short term statin treatment on left ventricular function and inflammatory markers in patients with chronic heart failure. Int. J. Cardiol. 123, 102-107 http://dx.doi.org/10.1016/j.ijcard.2006.11.152

Gutkowska J., Jankowski M., Antunes-Rodrigues J. (2014): The role of oxytocin in cardiovascular regulation. Braz. J. Med. Biol. Res. 47, 206-214 http://dx.doi.org/10.1590/1414-431X20133309

Houshmand F., Faghihi M., Zahediasl S. (2009): Biphasic protective effect of oxytocin on cardiac ischemia/reperfusion injury in anaesthetized rats. Peptide 30, 2301-2308 http://dx.doi.org/10.1016/j.peptides.2009.09.010

Iwamoto K., Chein C., Kato L. (1987): Effect of urethane anesthesia and age on organ blood flow in rats measured by hydrogen gas clearance method. J. Pharmacobiodyn. 10, 280-284 http://dx.doi.org/10.1248/bpb1978.10.280

John L. W. (2005): Nitric oxide as a regulator of inflammatory processes. Mem. Inst. Oswaldo Cruz, Rio de Janeiro 100, 5-9

Francis J., Chu Y., Johnson A. K., Weiss R. M., Felder R. B. (2004): Acute myocardial infarction induces hypothalamic 
cytokine synthesis. Am. J. Physiol. Heart Circ. Physiol. 286, 2264-2271

http://dx.doi.org/10.1152/ajpheart.01072.2003

Kewalramani G., Puthanveetil P., Wang F., Kim M. S., Deppe S., Abrahani A., Luciani D. S., Johnson J. D., Rodrigues B. (2009): AMP-activated protein kinase confers protection against TNF-a induced cardiac cell death. Cardiovasc. Res. 84, 42-53 http://dx.doi.org/10.1093/cvr/cvp166

Khatua T. N., Padiya R., Karnewar S., Kuncha M., Agawane S. B., Kotamraju S., Banerjee S. K. (2012): Garlic provides protection to mice heart against isoproterenol-induced oxidative damage: role of nitric oxide. Nitric Oxide 27, 9-17 http://dx.doi.org/10.1016/j.niox.2012.03.004

King J. (1965): The dehydrogenases or oxi-reductase - Lactate dehydrogenase. In: Practical Clinical Enzymology. van Nostrand, London

Lee Y., Gustafsson A. B. (2009): Role of apoptosis in cardiovascular disease. Apoptosis 14, 536-548 http://dx.doi.org/10.1007/s10495-008-0302-x

Madhesh M., Ramalingam R., Vaiyapuri M. (2011): Cardioprotective effect offenugreek on isoproterenol-induced myocardial infarction in rats. Indian J. Pharmacol. 43, 516-519 http://dx.doi.org/10.4103/0253-7613.84957

Mahammad R. S., Kodidhela L. D. (2013): Origination and development of isoproterenol- induced myocardial infarction in male Wistar rats. Int. Res. J. Pharm. 5, 26-36

Menaouar A., Florian M., Wang D., Danalache B., Jankowski M. (2014): Anti-hypertrophic effects of oxytocin in rat ventricular myocytes. Int. J. Cardiol. 175, 38-49 http://dx.doi.org/10.1016/j.ijcard.2014.04.174

Moghimian M., Faghihi M., Karimian S. M., Imani A. (2012): The effect of acute stress exposure on ischemia and reperfusion injury in rat heart: Role of oxytocin. Stress 15, 385-392 http://dx.doi.org/10.3109/10253890.2011.630436

Ndiaye K., Poole D. H., Pate J. L. (2008): Expression and regulation of functional oxytocin receptors in bovine Tlymphocytes. Biol. Reprod. 78, 786-793 http://dx.doi.org/10.1095/biolreprod.107.065938

Offerman E. L., Modell C. B., Dormandy T. L., Stocks J. B. (1972): The susceptibility to autoxidation of human red cell lipids in health and disease. J. Haematol. 23, 713-724 http://dx.doi.org/10.1111/j.1365-2141.1972.tb03486.x

Okinaka S., Kumagai H., Ebashi S., Sugita H., Momoi H., Toyokura Y., Fujie Y. (1961): Serum creatine phosphokinase. Activity in progressive muscular dystrophy and neuromuscular diseases. Arch. Neurol. 4, 520-525

http://dx.doi.org/10.1001/archneur.1961.00450110050006

Ovize M., Baxter G. F., Di L. F., Ferdinandy P., Garcia-Dorado D., Hausenloy D. J. (2010): Postconditioning and protection from reperfusion injury: where do we stand? Position paper from the Working Group of Cellular Biology of the Heart of the European Society of Cardiology. Cardiovasc. Res. 87, 406-423 http://dx.doi.org/10.1093/cvr/cvq129

Paglia D. E., Valentine W. E. (1967): Studies on quantitative and qualitative characterization of erythrocyte glutathione peroxidase J. Lab. Clin. Med. 70, 158-169
Palacios Callender M., Quintero M., Hollis V. S., Springett R. J., Moncada S. (2004): Endogenous NO regulates superoxide production at low oxygen concentrations by modifying the redox state of cytochrome c oxidase. Proc. Natl. Acad. Sci. USA 101, 7630-7635 http://dx.doi.org/10.1073/pnas.0401723101

Paul-Clark M. J., Roviezzo F., Flower R. J., Cirino G., Soldato P. D., Adcock I. M., Perretti M. (2003): Glucocorticoid receptor nitration leads to enhanced anti-inflammatory effects of novel steroid ligands. J. Immunol. 171, 3245-3252 http://dx.doi.org/10.4049/jimmunol.171.6.3245

Rajadurai M., Prince P. S. (2006): Preventive effect of naringin on lipids, lipoproteins and lipid metabolic enzymes in isoproterenol-induced myocardial infarction in Wistar rats. J. Biochem. Mol. Toxicol. 20, 191-197 http://dx.doi.org/10.1002/jbt.20136

Russell R. R., Li J., Coven D. L. , Pypaert M., Zechner C., Palmeri M., Giordano F. J., Mu J., Birnbaum M. J., Young L. H. (2004): AMP activated protein kinase mediates ischemic glucose uptake and prevents postischemic cardiac dysfunction, apoptosis, and injury. J. Clin. Invest. 114, 495-503 http://dx.doi.org/10.1172/JCI19297

Szeto A., Nation D. A., Mendez A. J., Dominguez-Bendala J., Brooks L. G., Schneiderman N., McCabe P. M. (2008): Oxytocin attenuates NADPH-dependent superoxide activity and IL-6 secretion in macrophages and vascular cells. Am. J. Physiol. Endocrinol. Metab. 295, 1495-1501 http://dx.doi.org/10.1152/ajpendo.90718.2008

Szeto A., Rossetti M. A., Mendez A. J., Noller C. M., Herderick E. E. (2013): Oxytocin administration attenuates atherosclerosis and inflammation in Watanabe Heritable Hyperlipidemic rabbits. Psychoneuroendocrinology 38, 685-693 http://dx.doi.org/10.1016/j.psyneuen.2012.08.009

Tawfik M. K., Ghattas M. H., Abo-Elmatty D. M., Abdel-Aziz N. A. (2010): Atorvastatin restores the balance between proinflammatory and anti-inflammatory mediators in rats with acute myocardial infarction. Eur. Rev. Med. Pharmacol. Sci.14, 499-506

Upaganlawar A., Gandhi H., Balaraman R. (2010): Effect of vitamin $\mathrm{E}$ alone and in combination with lycopene on biochemical and histopathological alterations in isoproterenol-induced myocardial infarction in rats. J. Pharmacol. Pharmacother. 1, 24-31 http://dx.doi.org/10.4103/0976-500X.64532

Whelan R. S., Kaplinskiy V., Kitsis R. N. (2010): Cell death in the pathogenesis of heart disease: mechanisms and significance. Annu Rev. Physiol. 72, 19-44 http://dx.doi.org/10.1146/annurev.physiol.010908.163111

Wsol A., Cudnoch-Jedrzejewska A., Szczepanska-Sadowska E., Kowalewski S., Puchalska L. (2008): Oxytocin in the cardiovascular responses to stress. J. Physiol. Pharmacol. 8, 123-127

Received: October 2, 2015

Final version accepted: November 19, 2015

First published online: May 26, 2016 